\title{
Posterior longitudinal ligament resection in anterior cervical discectomy
}

\author{
Ahmad Elsayed Desoukey Elayouty, Hazem Antar Mashaly and Hatem Adel Sabry
}

\begin{abstract}
Background: The concept of generous decompression, including resection of the posterior longitudinal ligament (PLL) and even partial bilateral uncovertebral joint resection, has been adopted by some authors. This was justified by the need to remove compressive structures hidden underneath and to prevent nerve root impingement during extreme flexion/extension or rotation. This study was designed to assess the benefits of PLL resection as a routine step in anterior cervical discectomy and fusion (ACDF) surgeries and to find out if there is any added risk of such a procedure that overweighs its benefits.
\end{abstract}

Methods: This is a retrospective study conducted on 50 patients who underwent ACDF for treatment of degenerative cervical intervertebral disc disease with microscopic resection of the posterior longitudinal ligament.

Results: There were 31 (62\%) males and 19 (38\%) females. Age ranged from 22 to 69 years with a mean age of 47.32 years. A total of 83 disc levels were operated upon with a mean of 1.66 levels per patient. Analysis of the obtained data showed a statistically significant difference between the preoperative and both early and late postoperative VAS ( $p$ value $<0.001$ for both). Moreover, there was a statistically significant difference between early and late postoperative VAS with a $p$ value $<0.001$. For axial neck pain, similar results could be demonstrated. Regarding motor function of related nerve roots, there was a statistically significant improvement in preoperative motor power grade values that can be demonstrated when compared with both the early and late postoperative grade values $(3.96 \pm 0.638,4.34 \pm 0.557$, and $4.88 \pm 0.328$ respectively).

Conclusions: Despite being an additional step in ACDF surgery, resection of the PLL does not seem to add significant surgical risk. On the other hand, it had a positive impact on outcome regarding axial and radicular pain. So, it may be advisable to attempt resection of the PLL as a routine step in ACDF surgery.

Keywords: Posterior longitudinal ligament, Anterior cervical discectomy, Cervical spine

\section{Background}

Spondylotic disease of the cervical spine is considered a well-known cause of neurological dysfunction. Herniation of intervertebral disc, osteophytosis, facet joints hypertrophy, and ligamentous thickening are documented pathological changes. The affected individuals are usually asymptomatic. However, $10-15 \%$ of cases may become symptomatic secondary to spinal cord and/ or nerve root compression [1].

Anterior cervical discectomy with fusion (ACDF) was introduced in the 1958 by Cloward and by Smith and

\footnotetext{
*Correspondence: dr.ahmad_elsayed@med.asu.edu.eg; dr.ahmad_elsayed@hotmail.com; dr.ahmad_elsayed@yahoo.com Department of neurosurgery, Faculty of Medicine, Ain Shams University, Cairo, Egypt
}

Robinson in early 1960s [1]. Since then, ACDF has been considered one of the most common surgical procedures in spinal surgery and a standard treatment for cervical radiculopathy and/or myelopathy [2]. In comparison to posterior approaches, ACDF has the advantages of being easier to perform allowing a wider exposure of the disc space together with less patient discomfort [3]. However, a rate of complications ranging from 8 to $20 \%$ has been reported, mostly attributed to the surgical approach and surgical corridor (such as dysphagia, voice changes, hematoma, and recurrent laryngeal nerve palsy) [4].

Anatomically, the posterior longitudinal ligament (PLL) lies on the posterior aspect of the vertebral bodies (Fig. 1). It is formed of two layers of fibrous tissue with the deep one sending fibers to the annulus fibrosus. 


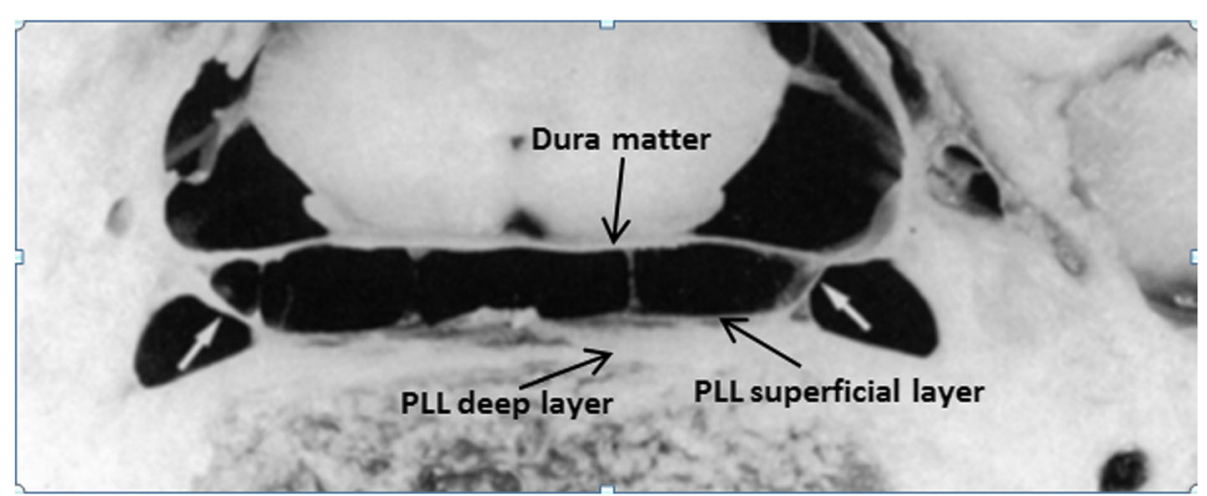

Fig. 1 A cadaveric cross section of the cervical spinal canal. The white arrow denotes the connection between the superficial layer of the PLL and the dura [5]

Laterally, it continues as a tough membrane that lines the intervertebral foramen and ends by merging with the anterior longitudinal ligament (ALL) at the anterior aspect of the foramen [5]. Being broader at the cervical region, the PLL becomes even more broader at the areas attached to the intervertebral discs and adjacent vertebral body where superficial and deep layers become inseparable [6]. Additionally, the PLL is a very tough structure that seldom ruptures. On the other hand, it is not uncommon that the annulus fibrosus ruptures resulting in fragments of nucleus pulposus that can be extruded out at the vertebral rim and get beneath the PLL [7].

The concept of generous decompression, including resection of the posterior longitudinal ligament (PLL) and even partial bilateral uncovertebral joints resection, has been adopted by some authors. This was justified by the need to remove compressive structures hidden underneath and to prevent nerve roots impingement during extreme flexion/extension or rotation [8]. It is also to be mentioned that none of the authors had any competing interests regarding the current study.

\section{Aim of the study}

This study was designed to assess for benefits of PLL resection as a routine step in ACDF surgeries and to find out if there is any added risk of such procedure that overweighs its benefits.

\section{Methods}

This is a retrospective study conducted on 50 patients who underwent ACDF for treatment of degenerative cervical intervertebral disc disease operated upon at Ain Shams University hospitals from January 2008 to February 2017.

An approval from the research ethics committee of the Faculty of Medicine at Ain Shams University (reference number: FWA 00006444) was obtained. Furthermore, being a retrospective study, patients' consents for participation and for publication were not applicable.

Additionally, each one of the co-authors had neither a financial nor a non-financial competing interest to report.

All disc levels were included down from $\mathrm{C} 2-3$ level to C6-7 disc level, and patients having multilevel disc disease were also included. All of the included patients failed to show satisfactory improvement on nonsurgical treatment modalities or had progressive neurological deficits. On the other hand, patients having traumatic, neoplastic, or inflammatory pathologies were excluded. In addition, patients having ossification of posterior longitudinal ligament (OPLL) were also excluded. Moreover, patients with evident instability on plain radiographs were excluded.

A thorough review of the preoperative clinical and radiological data for all enrolled patients was performed. Clinically, radicular and long tracts' motor and sensory functions were documented. Visual analogue scores (VAS) were viewed for assessment of radicular and axial neck pains. Radiological assessment included plain radiographs (antero-posterior, lateral, and dynamic views) and magnetic resonance images (MRI). Moreover, a thin cut computerized tomography (CT) scan was ordered in certain situations to assess for bony anatomy or to exclude other pathologies as OPLL.

A standard microscopic anterior cervical discectomy was performed according to the Smith-Robison technique [9]. Adequate removal of posterior osteophytes was routinely attempted using high-speed drill, curettes, and kerrison bone rongeurs. In each one of the operated levels, the PLL was identified and dissected from the underlying dura and epidural membrane using microcurettes and blunt-ended hooks. The PLL was then resected using kerrison bone rongeurs of 1 and/or $2 \mathrm{~mm}$ size until the dura is clearly exposed from one intervertebral foramen to the other (Fig. 2). In the vast majority 


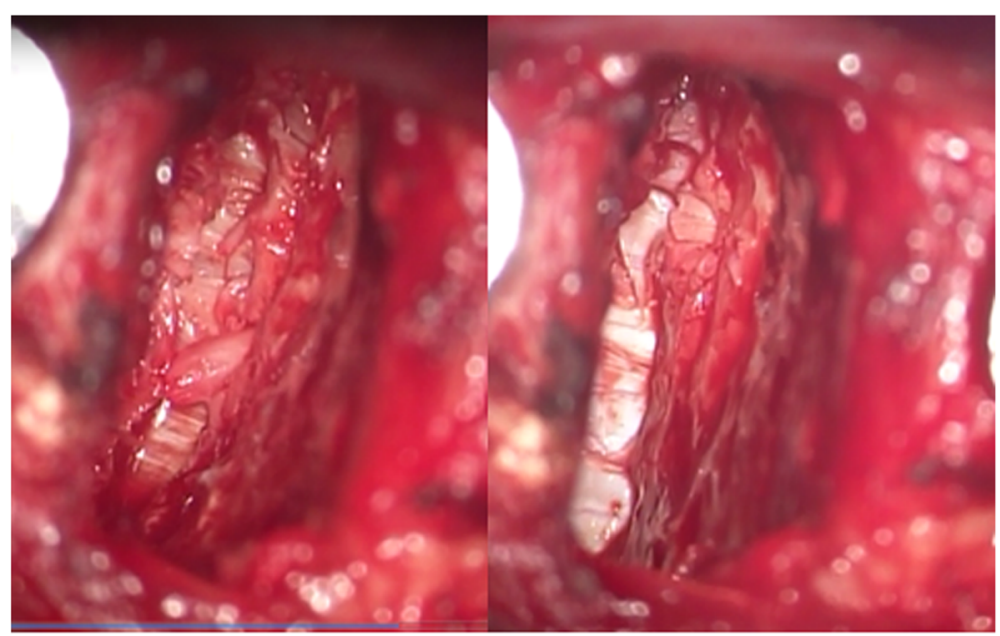

Fig. 2 Intraoperative photograph before (left) and after (right) resection of the PLL

of cases, the dura could be easily dissected from the overlying PLL once the proper plane is entered. However, in a few number of cases, attempts to completely separate the PLL from the underlying dura were apparently unsafe and an island of the adherent PLL had to be left in place after separating it from the surrounding tissues and minimizing its thickness as much as possible. Troublesome epidural bleeding was sometimes encountered and was adequately controlled by gentle compression using a cottonoid patty and/or temporary use of a hemostatic agent. Polyetheretherketone (PEEK) cage filled with a synthetic bone graft substitutes was always used for fusion.

The postoperative clinical data were analyzed for assessment of changes in the initial data and for any procedure-related complications. Additionally, postoperative plain radiographs were viewed to check for proper disc space distraction and cage position. Postoperative assessment was routinely carried out immediately postoperative (within the first $48 \mathrm{~h}$ prior to patient discharge), at 2 weeks interval and after 3 months. However, only the data from the immediate (considered early postoperative) and the 3 months (considered late postoperative) interval assessments were included in the current study.

\section{Statistical analysis}

Collected data were expressed as mean \pm standard deviation and range and compared via the paired student $t$ test using SOFA statistics version 1.3.3 software.

\section{Results}

Out of the 50 patients enrolled in the current study, there were 31 (62\%) males and 19 (38\%) females. Age ranged from 22 to 69 years with a mean age of 47.32 years (Additional file 1). A total of 83 disc levels were operated upon with a mean of 1.66 levels per patient. A single level was operated in 25 patients (50\%) while 17 patients (34\%) had double-level surgery and 8 patients (16\%) had triple-level surgery. The most frequently operated level was 5-6 disc level $(n=33)$ followed by 3-4 disc level $(n=18), 6-7$ level $(n=17)$, and $4-5$ level $(n=15)$. The mean preoperative, early postoperative, and late postoperative VAS for radicular pain values are illustrated in Table 1. Analysis of such data showed a statistically significant difference between the preoperative and both early and late postoperative VAS ( $p$ value $<0.001$ for both). Moreover, there was a statistically significant difference between early and late postoperative VAS with a $p$ value $<0.001$.

Moreover, analysis of preoperative, early postoperative, and late postoperative VAS for axial neck pain values showed a statistically significant difference between preoperative and early postoperative, preoperative and late postoperative, and between early and late postoperative values with a $p$ value $<0.001$ for each comparison. Table 2 illustrates different data for axial neck pain.

Table 1 Comparison between different values of VAS for radicular pain

\begin{tabular}{|c|c|c|c|c|c|}
\hline & Min & Max & Mean \pm Std Dev & $95 \% \mathrm{Cl}$ & $p$ value \\
\hline \multirow{2}{*}{$\begin{array}{l}\text { Preoperative VAS for } \\
\text { radicular pain VS early } \\
\text { postoperative VAS } \\
\text { for radicular pain }\end{array}$} & 5.0 & 10.0 & $7.74 \pm 1.31$ & $7.378-8.102$ & \multirow[t]{2}{*}{$<0.001$} \\
\hline & 1.0 & 5.0 & $2.36 \pm 0.90$ & $2.111-2.609$ & \\
\hline \multirow{2}{*}{$\begin{array}{l}\text { Preoperative VAS for } \\
\text { radicular pain vs late } \\
\text { postoperative VAS } \\
\text { for radicular pain }\end{array}$} & 5.0 & 10.0 & $7.74 \pm 1.31$ & $7.378-8.102$ & \multirow[t]{2}{*}{$<0.001$} \\
\hline & 0.0 & 3.0 & $0.56 \pm 0.79$ & $0.342-0.778$ & \\
\hline \multirow{2}{*}{$\begin{array}{l}\text { Early postoperative } \\
\text { VAS for radicular } \\
\text { pain vs late } \\
\text { postoperative VAS } \\
\text { for radicular pain }\end{array}$} & 1.0 & 5.0 & $2.36 \pm 0.90$ & $2.111-2.609$ & \multirow[t]{2}{*}{$<0.001$} \\
\hline & 0.0 & 3.0 & $0.56 \pm 0.79$ & $0.342-0.778$ & \\
\hline
\end{tabular}


Table 2 Comparison between different values of VAS for axial neck pain

\begin{tabular}{|c|c|c|c|c|c|}
\hline & Min & Max & $\begin{array}{l}\text { Mean } \pm \text { Std } \\
\text { Dev }\end{array}$ & $95 \% \mathrm{Cl}$ & $p$ value \\
\hline \multirow{2}{*}{$\begin{array}{l}\text { Preoperative VAS for } \\
\text { axial neck pain vs early } \\
\text { postoperative VAS for } \\
\text { axial neck pain }\end{array}$} & 6.0 & 9.0 & $7.44 \pm 0.951$ & $7.176-7.704$ & \multirow[t]{2}{*}{$<0.001$} \\
\hline & 2.0 & 6.0 & $3.96 \pm 0.90$ & $3.648-4.272$ & \\
\hline \multirow{2}{*}{$\begin{array}{l}\text { Preoperative VAS } \\
\text { for axial neck } \\
\text { pain vs late } \\
\text { postoperative VAS } \\
\text { for axial neck pain }\end{array}$} & 6.0 & 9.0 & $7.44 \pm 0.951$ & 7.176-7.704 & \multirow[t]{2}{*}{$<0.001$} \\
\hline & 0.0 & 3.0 & $1.34 \pm 0.717$ & $1.141-1.539$ & \\
\hline \multirow{2}{*}{$\begin{array}{l}\text { Early postoperative } \\
\text { VAS for axial neck } \\
\text { pain vs late postoperative } \\
\text { VAS for axial neck pain }\end{array}$} & 2.0 & 6.0 & $3.96 \pm 0.90$ & $3.648-4.272$ & \multirow[t]{2}{*}{$<0.001$} \\
\hline & 0.0 & 3.0 & $1.34 \pm 0.717$ & $1.141-1.539$ & \\
\hline
\end{tabular}

Regarding motor function of related nerve roots, the whole patient population showed no postoperative deterioration in pertinent root value power grades. On the other hand, there was a statistically significant improvement in preoperative motor power grade values that can be demonstrated when compared with both the early and late postoperative grade values (Tables 3 and 4 respectively). Figure 3 is a chart that illustrates different motor power grade values at preoperative, early postoperative, and late postoperative assessments.

Fortunately, accidental dural injury complicated with either intraoperative or postoperative cerebrospinal fluid leakage was not encountered in any case. Moreover, symptomatic epidural hematoma necessitating further management was not documented for any of the included patients. Superficial wound infection complicated two (4\%) surgeries and was adequately controlled by local wound care and systemic antibiotics with no longterm sequelae of such incidents.

\section{Discussion}

From the aforementioned results, it can be hypothesized that despite having an additional surgical maneuver in dissection and resection of the PLL, there was no significant added risk. Furthermore, a satisfactory clinical patient outcome could be achieved as demonstrated by comparison between patients' preoperative and postoperative data.

Table 3 Comparison between preoperative and early postoperative values of radicular motor power

\begin{tabular}{llll}
\hline & $N$ & $\begin{array}{l}\text { Mean } \pm \text { standard } \\
\text { deviation }\end{array}$ & $95 \% \mathrm{Cl}$ \\
\hline $\begin{array}{l}\text { Preoperative radicular } \\
\text { motor power }\end{array}$ & 50 & $3.96 \pm 0.638$ & $3.783-4.137$ \\
$\begin{array}{l}\text { Early postoperative } \\
\text { radicular motor power }\end{array}$ & 50 & $4.34 \pm 0.557$ & $4.186-4.494$ \\
\hline$p$ value $<0.001$ & & &
\end{tabular}

Table 4 Comparison between preoperative and late postoperative values of radicular motor power

\begin{tabular}{lclc}
\hline & $N$ & $\begin{array}{l}\text { Mean } \pm \text { standard } \\
\text { deviation }\end{array}$ & $95 \% \mathrm{Cl}$ \\
\hline $\begin{array}{l}\text { Preoperative radicular } \\
\text { motor power }\end{array}$ & 50 & $3.96 \pm 0.638$ & $3.783-4.137$ \\
$\begin{array}{l}\text { Late postoperative } \\
\text { radicular motor power }\end{array}$ & 50 & $4.88 \pm 0.328$ & $4.789-4.971$ \\
\hline$p$ value $<0.001$ & & &
\end{tabular}

In addition, there were no mortalities recorded related to surgeries.

In their study for the functional outcome of ACDF for a single-level cervical disc disease, Kamani et al. [1] reported that the age group which was most commonly affected was between 40 and 50 years in our study and this was comparable to our results (mean age of $47.32 \pm 9.23$ years). Additionally, both our and their studies agreed on male predominance and on that 5-6 disc level was the most common level operated upon.

Adogwa et al. [4] compared microscopic to nonmicroscopic anterior cervical discectomies. In comparison to their microscopic arm of 59 patients, the results of our study were comparable regarding age $(54.50 \pm 13.29)$ and male predominance $(52.54 \%)$. Regarding axial neck pain, they reported a preoperative mean VAS of $4.85 \pm 2.93$ compared to $7.44 \pm 0.951$ in the current study. However, the 3 months postoperative VAS for axial neck pain was higher in their study $(2.88 \pm 2.92$ versus $1.34 \pm 0.717)$. They also reported no incidents of nerve root injury nor accidental durotomy.

Lin and coworkers [10] studied the effect of PLL resection in ACDF surgery on disc-associating axial pain. They had a preoperative VAS for axial neck pain of 6.06 \pm 0.61 and a postoperative VAS for axial neck pain of 3 . $15 \pm 0.63$, and they concluded that intervertebral PLL can be considered the origin of such pain.

In a study on long-term results of ACDF conducted by Kim et al. [11], it was reported that the preoperative mean VAS for radicular and axial neck pain for noncage subsidence patients $(n=61)$ is $7.30 \pm 2.36$ and 6.23 \pm 3.05 , respectively, compared to $7.74 \pm 1.31$ and $7.44 \pm$ 0.951 in the current study. Indeed, they had a longer follow-up period, but the postoperative results of the same parameters were better in our results $(2.06 \pm 1.95$ versus $0.56 \pm 0.79$ for radicular pain and $1.35 \pm 1.22$ versus $1.34 \pm 0.717$ for axial neck pain). The difference was more evident for the radicular pain, and this can be explained by a presumably more generous foramenotomy that can be guaranteed after resection of the PLL.

In a meta-analysis for the prevalence of complications after surgery in treatment for cervical compressive myelopathy, Wang et al. [12] reported a 5.3\% incidence rate for C5 nerve root injury, a $1.9 \%$ incidence of 


\section{Chart 1: radicular motor power grades}

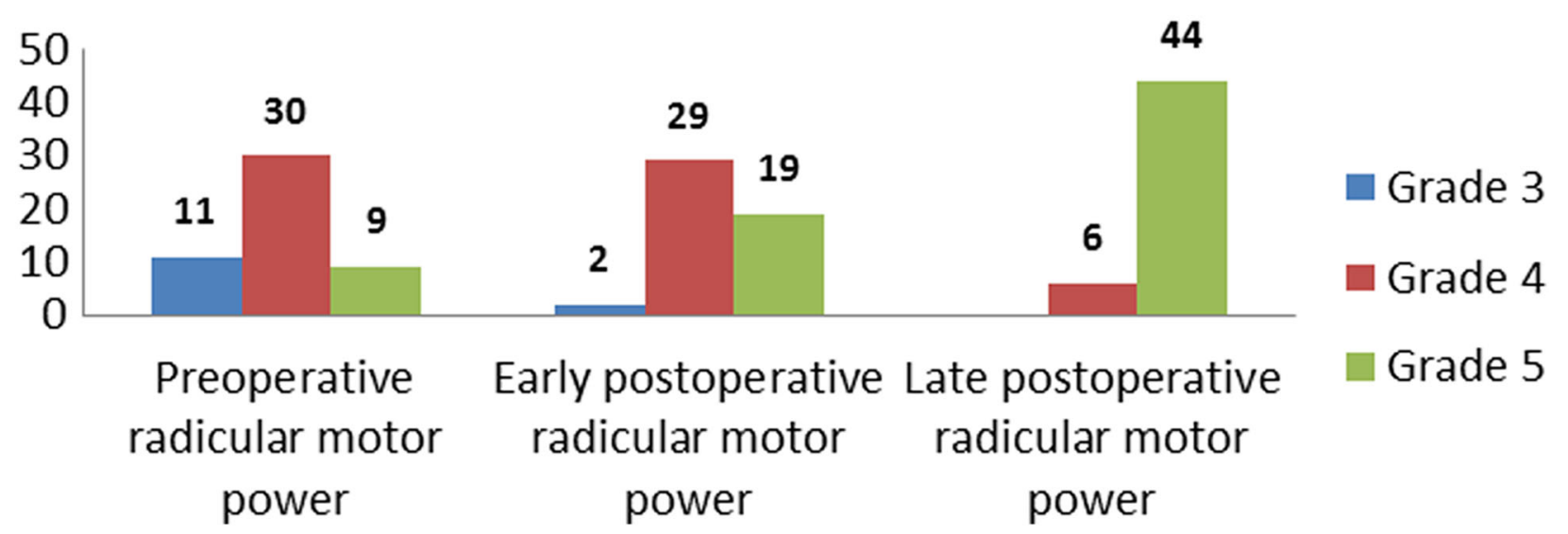

Fig. 3 A chart illustrating different values of radicular motor power grades

cerebrospinal fluid leak, a $2.8 \%$ infection rate, and a 1 . $1 \%$ incidence rate for development of epidural hematoma. In the current study, the radicular motor function improved significantly (Tables 3 and 4) with no clinical evidence of nerve root injury. Moreover, there were no cases complicated with neither cerebrospinal fluid leak nor epidural hematoma and the superficial infection rate was $4 \%$.

The limitations of our study include its retrospective nature, the lack of randomization, and the absence of data necessary for a comparison with a control group of patients.

\section{Conclusions}

Despite being an additional step in ACDF surgery, resection of the PLL does not seem to add significant surgical risk. On the other hand, it had a positive impact on outcome regarding axial and radicular pain. So, it may be advisable to attempt resection of the PLL as a routine step in ACDF surgery.

\section{Additional file}

Additional file 1: The excel file containing the data from the included patients. (XLSX $13 \mathrm{~kb})$

\section{Abbreviations}

ACDF: Anterior cervical discectomy with fusion; ALL: Anterior longitudinal ligament; CT: Computerized tomography; MRI: Magnetic resonance images; OPLL: Ossification of posterior longitudinal ligament;

PEEK: Polyetheretherketone; PLL: Posterior longitudinal ligament; VAS: Visual analogue scores

\section{Availability of data and materials}

The dataset supporting the conclusions of this article is included within the article (and its Additional file 1).

\section{Authors' contributions}

The main author (AEDE) had a substantial role in the study design, data acquisition, and interpretation. In addition, the first co-author (HAM) actively participated in the data acquisition, interpretation, and revision of the manuscript while the second co-author (HAS) was involved critically in the study design, data acquisition, and drafting of the manuscript. All authors read and approved the final manuscript.

Ethics approval and consent to participate

An approval from the research ethics committee of the Faculty of Medicine at Ain Shams University (reference number: FWA 00006444) was obtained. Being a retrospective study, patients' consents for participation were not applicable.

\section{Competing interests}

The authors declare that they have no competing interests.

\section{Publisher's Note}

Springer Nature remains neutral with regard to jurisdictional claims in published maps and institutional affiliations.

Received: 11 October 2017 Accepted: 4 April 2018

Published online: 02 May 2018

\section{References}

1. Kamani MM, Ballal A, Shetty V, Rai HR, Hegde D. A prospective study of the functional outcome of anterior cervical discectomy with fusion in single level degenerative cervical disc prolapse. J Clin Diagn Res. 2016;10(5):Rc01-4.

2. Basques BA, Ondeck NT, Geiger EJ, Samuel AM, Lukasiewicz AM, Webb ML, et al. Differences in short-term outcomes between primary and revision anterior cervical discectomy and fusion. Spine. 2017;42(4):253-60.

3. Liu WJ, Hu L, Chou PH, Wang JW, Kan WS. Comparison of anterior cervical discectomy and fusion versus posterior cervical foraminotomy in the treatment of cervical radiculopathy: a systematic review. Orthop Surg. 2016; 8(4):425-31

4. Adogwa O, Elsamadicy A, Reiser E, Ziegler C, Freischlag K, Cheng J, et al. Comparison of surgical outcomes after anterior cervical discectomy and fusion: does the intra-operative use of a microscope improve surgical outcomes. J Spine Surg (Hong Kong). 2016;2(1):25-30.

5. Hayashi K, Yabuki T, Kurokawa T, Seki H, Hogaki M, Minoura S. The anterior and the posterior longitudinal ligaments of the lower cervical spine. J Anat. 1977;124(Pt 3):633-6.

6. Loughenbury PR, Wadhwani S, Soames RW. The posterior longitudinal ligament and peridural (epidural) membrane. Clin Anat (New York, NY). 2006:19(6):487-92.

7. Wiltse LL, Fonseca AS, Amster J, Dimartino P, Ravessoud FA. Relationship of the dura, Hofmann's ligaments, Batson's plexus, and a fibrovascular membrane lying on the posterior surface of the vertebral bodies and attaching to the deep layer of the posterior longitudinal ligament. An anatomical, radiologic, and clinical study. Spine. 1993;18(8):1030-43. 
8. Tu TH, Chang CC, Wu JC, Fay LY, Huang WC, Cheng H. Resection of uncovertebral joints and posterior longitudinal ligament for cervical disc arthroplasty. Neurosurg Focus. 2017;42(VideoSuppl1):V2.

9. Smith GW, Robinson RA. The treatment of certain cervical-spine disorders by anterior removal of the intervertebral disc and interbody fusion. J Bone Joint Surg Am. 1958;40-a(3):607-24.

10. Lin $W$, Xue $Y$, Zhao $Y$, Zong $Y$, Sun C, Pei B, et al. Disc associating axial pain were indicated by PLL resection in ACDF surgery. European spine journal: official publication of the European Spine Society, the European Spinal Deformity Society, and the European Section of the Cervical Spine Research Society. 2017;26(4):1211-6.

11. Kim WB, Hyun SJ, Choi H, Kim KJ, Jahng TA, Kim HJ. Long-term follow-up results of anterior cervical inter-body fusion with stand-alone cages. J Korean Neurosurg Soc. 2016;59(4):385-91.

12. Wang $T$, Tian XM, Liu SK, Wang H, Zhang YZ, Ding WY. Prevalence of complications after surgery in treatment for cervical compressive myelopathy: a meta-analysis for last decade. Medicine. 2017;96(12):e6421.

\section{Submit your manuscript to a SpringerOpen ${ }^{\circ}$ journal and benefit from:}

- Convenient online submission

- Rigorous peer review

- Open access: articles freely available online

- High visibility within the field

- Retaining the copyright to your article

Submit your next manuscript at $\boldsymbol{s p r i n g e r o p e n . c o m ~}$ 